\title{
Detection of SARS-CoV-2 in formalin-fixed paraffin-embedded tissue sections using commercially available reagents
}

\author{
Alejandro Best Rocha ${ }^{1} \cdot$ Edana Stroberg $^{2} \cdot$ Lisa M. Barton ${ }^{2} \cdot$ Eric J. Duval $^{2}$ - Sanjay Mukhopadhyay ${ }^{3}$. \\ Nicole Yarid $\mathbb{D}^{4} \cdot$ Tiffany Caza $^{1} \cdot$ Jon D. Wilson ${ }^{1} \cdot$ Daniel J. Kenan $\mathbb{D}^{1} \cdot$ Michael Kuperman ${ }^{1} \cdot$ Shree G. Sharma ${ }^{1}$. \\ Christopher P. Larsen (10) ${ }^{1}$
}

Received: 27 May 2020 / Revised: 19 June 2020 / Accepted: 22 June 2020 / Published online: 9 July 2020

(c) The Author(s), under exclusive licence to United States and Canadian Academy of Pathology 2020

\begin{abstract}
Coronavirus Disease-19 (COVID-19), caused by the coronavirus SARS-CoV-2, was initially recognized in Wuhan, China and subsequently spread to all continents. The disease primarily affects the lower respiratory system, but may involve other organs and systems. Histopathologic evaluation of tissue from affected patients is crucial for diagnostic purposes, but also for advancing our understanding of the disease. For that reason, we developed immunohistochemical (IHC) and in situ hybridization (ISH) assays for detection of the. virus. A total of eight autopsy lungs, one placenta, and ten kidney biopsies from COVID-19 patients were stained with a panel of commercially available antibodies for IHC and commercially available RNA probes for ISH. Similarly, autopsy lungs, placentas and renal biopsies from non-COVID-19 patients were stained with the same antibodies and probes. All eight lungs and the placenta from COVID-19 patients stained positive by IHC and ISH, while the kidney biopsies stained negative by both methodologies. As expected, all specimens from nonCOVID-19 patients were IHC and ISH negative. These two assays represent a sensitive and specific method for detecting the virus in tissue samples. We provide the protocols and the list of commercially available antibodies and probes for these assays, so they can be readily implemented in pathology laboratories and medical examiner offices for diagnostic and research purposes.
\end{abstract}

\section{Introduction}

Coronavirus Disease 2019 (COVID-19), a primarily respiratory and occasionally multisystemic disease, is caused by the novel beta-coronavirus Severe Acute Respiratory Syndrome coronavirus 2 (SARS-CoV-2) $[1,2]$. Similar to the coronaviruses SARS-CoV responsible for Severe Acute Respiratory Syndrome (SARS) and MERS-CoV responsible for Middle East Respiratory Syndrome (MERS), SARS-CoV-2 is a highly pathogenic virus that is transmitted remarkably effectively and has

Christopher P. Larsen

Chris.larsen@arkanalabs.com

Arkana Laboratories, Little Rock, AR, USA

2 Oklahoma Office of the Chief Medical Examiner, Oklahoma City, OK, USA

3 Cleveland Clinic, Cleveland, OH, USA

4 King County Medical Examiner's Office, Seattle, WA, USA spread rapidly around the world after its initial recognition in Wuhan, Hubei Province, China [1, 3]. Recently, autopsy case series and biopsy specimens from patients with COVID-19 have been presented in the literature [4-7]. Analysis of tissue from human subjects is important in advancing our understanding of the pathogenesis of this disease [8]. We have developed immunohistochemical (IHC) and in situ hybridization (ISH) assays that can be used for tissue identification of the virus and assessment of its distribution among different sites and tissue types. Here we provide the protocols for such assays, which can be implemented in the most anatomic pathology laboratories. We also share the commercially available antibodies and probes that were found to effectively detect SARS-CoV-2 in our laboratory.

\section{Methods}

The study protocol conformed to the Declaration of Helsinki principles and all study protocols were Institutional 
Table 1 Commercial antibodies and probes for SARS-CoV-2 detection.

\begin{tabular}{llll}
\hline Company & Product \# & Listed target & Dilution \\
\hline ACDBio & 848568 & SARS-CoV-2 RNA (21631-23303) & Ready to use \\
Bioss & BSM-41411M & Recombinant SARS-CoV-2 Nucleocapsid protein (His-tag) & $1: 100$ \\
Bioss & BSM-49131M & Recombinant SARS Nucleocapsid protein (no tag) & $1: 400$ \\
Thermo & MA1-7404 & SARS nucleoprotein preparation & $1: 100$ \\
\hline
\end{tabular}

Table 2 Tissue samples from patients with COVID-19 stained by IHC and ISH.

\begin{tabular}{lll}
\hline Organ (number of samples) & \# Positive by IHC & \# Positive by ISH \\
\hline $\begin{array}{l}\text { Lung from decedents with } \\
\text { COVID-19 (8) }\end{array}$ & 8 & 8 \\
$\begin{array}{l}\text { Placenta from patient with } \\
\text { active COVID-19 (1) }\end{array}$ & 1 & 1 \\
$\begin{array}{l}\text { Kidney from patient with } \\
\text { active COVID-19 (10) }\end{array}$ & 0 & 0
\end{tabular}

Review Board approved. All IHC assays were performed on the Leica BOND-III platform (Leica, Wetzlar, Germany) using formalin-fixed paraffin-embedded specimens sectioned at 3 microns onto positively charged glass slides. IHC antigen retrieval was performed using BOND Epitope Retrieval Solution 2 (prediluted, pH 9.0; AR 9640) for $20 \mathrm{~min}$ at $100^{\circ} \mathrm{C}$. Specimens were incubated with primary rabbit or mouse antibodies (suppliers and appropriate dilutions provided in Table 1) for $15 \mathrm{~min}$ at room temperature, followed by visualization with the Leica Bond detection kit at room temperature (DS 9800). The specimens were then counterstained with hematoxylin.

RNA ISH was performed on the Leica BOND-III platform (Leica, Wetzlar, Germany) using RNAScope probes (ACD, Newark, CA) directed against SARS-CoV2, targeting 21631-23303 base pairs [9]. A negative control probe to the bacterial gene diaminopimelate $\mathrm{B}$ (DapB) was utilized to assess non-specific background signals, as well as a positive control probe to the housekeeping gene peptidylprolyl isomerase B (PPIB) for RNA integrity were included within each run. The Leica Bond RNAscope detection kit (catalog \#DS9790) was utilized per manufacturer's instructions and is described below. Tissue retrieval was performed at $95^{\circ} \mathrm{C}$ for $15 \mathrm{~min}$ followed by incubation with RNAscope protease for $15 \mathrm{~min}$ at $40^{\circ} \mathrm{C}$. Probes were added and hybridized for $3 \mathrm{~h}$ at $42^{\circ}$ $\mathrm{C}$, using the following protocol AMP1 3,3'-diaminobenzidine (DAB) (incubated for $30 \mathrm{~min}$ ), AMP2 DAB (15 min), AMP3 DAB (30 min), AMP4 DAB (for $15 \mathrm{~min}$ ), AMP5 DAB (30 min), and AMP6 DAB (15 min) were incubated followed by incubation with $\mathrm{DAB}$ for 20 min. Sections were counterstained with periodic acidSchiff.

\section{Results}

Tissue from patients with COVID-19 and control samples were studied by both IHC and ISH. The samples from patients with known COVID-19 infections included eight autopsy lung samples, one placenta, and ten renal biopsies. Control samples from patients without COVID-19 including autopsy lungs, renal biopsies, and placenta samples were also tested (Table 2). The antibodies and probes that were found to be sensitive and specific for the detection of SARS-CoV-2 are listed in Table 1 along with the dilution used for detection.

Both IHC and ISH showed a similar pattern of reactivity in all tissue samples from patients with COVID-19, with complete concordance. All autopsy lung samples showed focally positive cells for SARS-CoV-2 (Fig. 1). Because strong staining obscured the morphologic details of the positive cells, it was not always possible to determine with certainty whether the positive cells were alveolar pneumocytes or capillary endothelial cells. However, based on the shape of the positive cells and their protrusion into airspaces from the edges of alveolar septa, we interpreted them as alveolar pneumocytes. The placenta showed strong positive staining of syncytiotrophoblasts and cytotrophoblasts by both assays. The kidney samples from COVID-19 samples were IHC and ISH negative (Fig. 2). Tissue samples from all patients without COVID-19 were all negative, including 5 autopsy lungs, 5 placentas, and 15 kidneys. There was 100\% agreement between the IHC and ISH assays for the detection of SARS-CoV-2 in all specimen types (Table 2). All negative control slides were negative within the areas that stained positive by both IHC and ISH.

\section{Discussion}

Histopathologic evaluation of biopsy and autopsy material from COVID-19 patients is of critical importance to understand the pathophysiology and distribution of the virus within different organs and tissue types. The most remarkable and best-described microscopic changes involve the lungs, where affected patients frequently show characteristic findings of early to more advanced stages of diffuse alveolar damage, severe capillary congestion and 

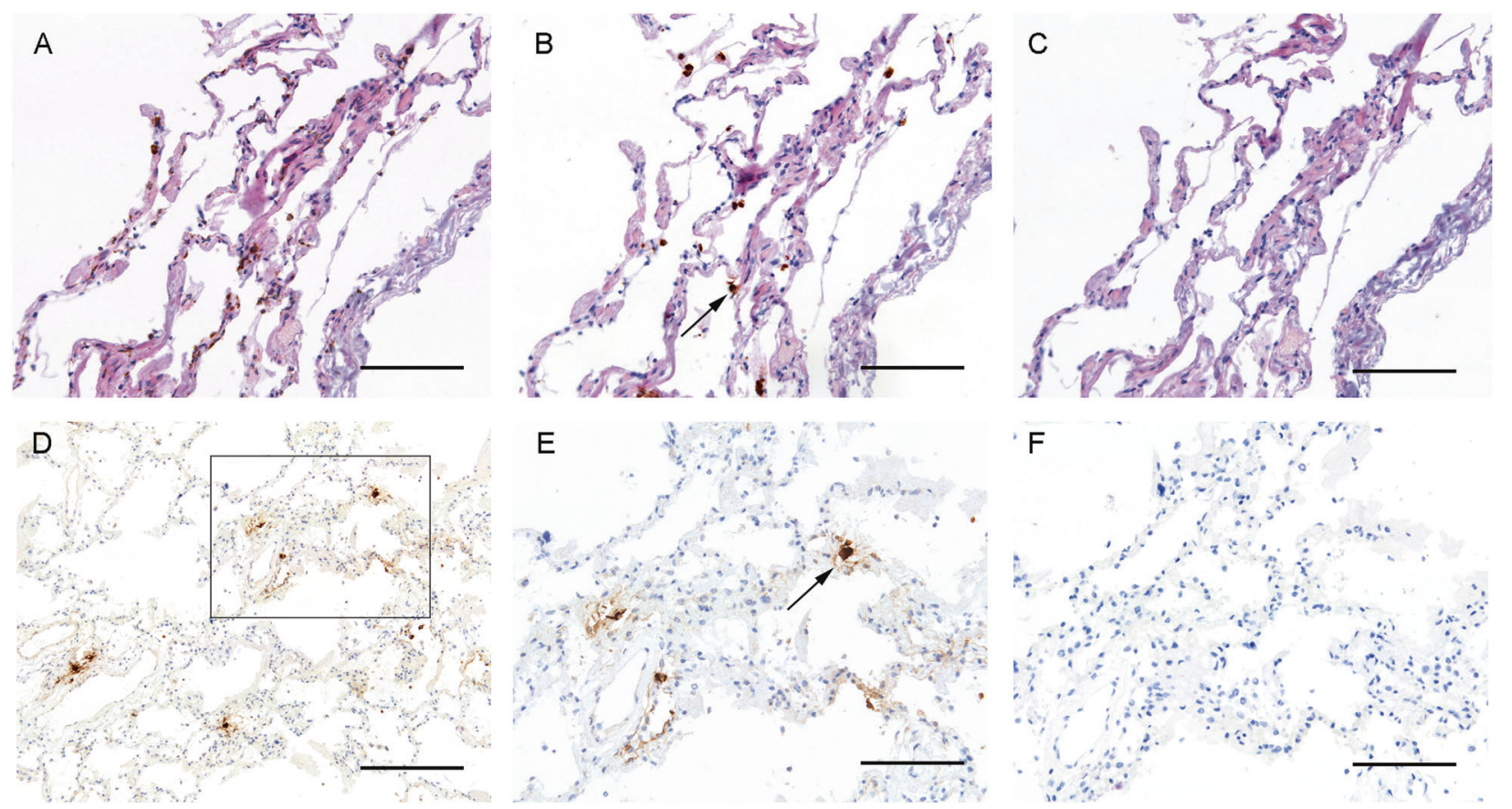

Fig. 1 SARS-CoV-2 IHC and ISH in lung. SARS-CoV-2 ISH (a-c) and IHC (d-f) in lung parenchyma from the autopsy of a patient who died secondary to COVID-19. Positive reaction for the (a) control probes to the housekeeping gene peptidylprolyl isomerase $\mathrm{B}(P P I B)$ by in situ hybridization confirms the presence of intact nucleic acid. b There is a positive reaction for the probes directed against SARS$\mathrm{CoV}-2$ (arrow) and $\mathbf{c}$ a negative reaction for the negative control probes (bacterial gene dapB) in a serial section (Periodic acid-Schiff counterstain; original magnifications $\times 200$; bar $=50 \mu \mathrm{m}$ ). d-f Immunohistochemical analysis for SARS-CoV-2 is positive (arrow) in the tissue (d with higher power of outlined region in e) with negative staining in the $\mathbf{f}$ negative control (hematoxylin counterstain; original magnifications $\times 100$ in $\mathrm{D}$ and $\times 200$ in $\mathbf{e}$ and $\mathbf{f}$; $b a r=100 \mu \mathrm{m}$ in $\mathbf{d}$ and bar $=50 \mu \mathrm{m}$ in $\mathbf{e}$ and $\mathbf{f}$ ).
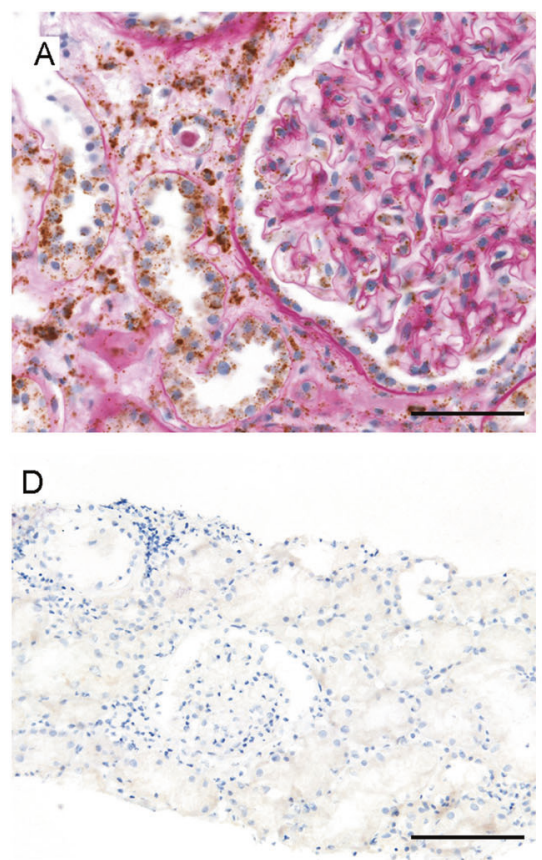
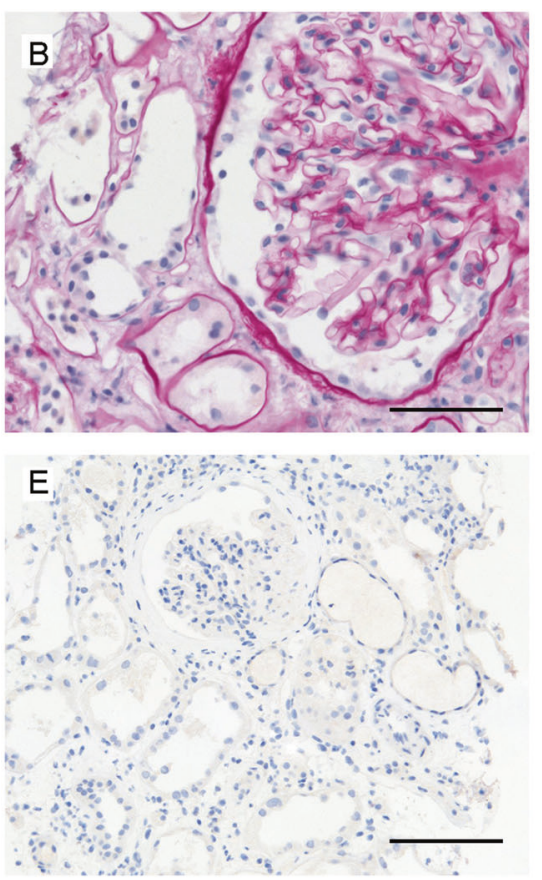
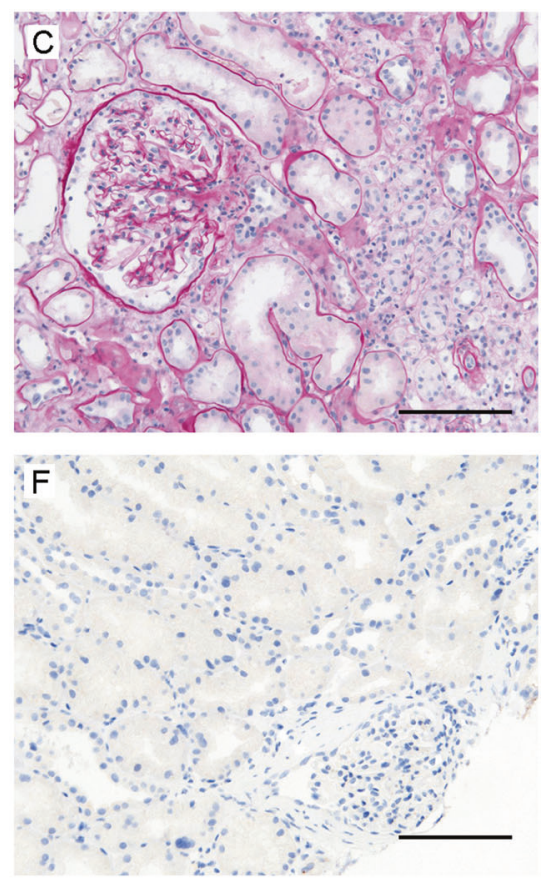

Fig. 2 SARS-CoV-2 IHC and ISH in kidney. ISH in a renal biopsy tissue from a patient with active COVID-19 at the time of biopsy shows (a) reactivity for the positive control probe to the housekeeping gene peptidylprolyl isomerase $\mathrm{B}(P P I B)$ (original magnification $\times 400$; $\mathrm{bar}=25 \mu \mathrm{m})$ and $\mathbf{b}, \mathbf{c}$ negativity for the presence of SARS-CoV-2 RNA (Periodic acid-Schiff counterstain; original magnifications $\times 400$ and $\times 200$; bar $=25 \mu \mathrm{m}$ for $\mathrm{B}$ and $\mathrm{bar}=50 \mu \mathrm{m}$ for $\mathbf{c}$ ). $\mathbf{d}-\mathbf{f}$ IHC staining of renal biopsy tissue from three different patients with active COVID-19 at the time of biopsy shows negative staining in the parenchyma (hematoxylin counterstain; original magnification $\times 200$; bars $=50 \mu \mathrm{m})$. 
occasionally, superimposed bronchopneumonia [6, 10]. This observation is not surprising given that the main clinical manifestations involve the lower respiratory system. However, patients may present with extrapulmonary signs and symptoms, signaling involvement of the gastrointestinal, genitourinary, cardiovascular, and nervous systems [11-15]. The post-mortem biopsy study of Tian et al. showed that organs such as the liver and heart, even when positive for SARS-CoV-2 by RT-PCR, showed only mild, non-specific histopathologic changes by light microscopic examination [6]. Electron microscopy studies have been reported to have some utility to identify viral particles in affected tissue; however, only few centers have access to this technology, and identification of viral-like particles by this methodology is controversial $[16,17]$. Therefore, testing methodologies that are readily available to pathology practices, medical examiner's offices, and researchers, such as IHC and ISH, will be essential in understanding organ involvement and cell-type specific infections by SARSCoV-2.

During the 2002-2003 SARS outbreak, ISH and IHC assays were developed for research and diagnostic purposes, and the tissue and cellular tropism of SARS-CoV-2 was determined [18, 19]. Due to the need for ancillary diagnostic tissue testing during the COVID-19 pandemic, Liu et al developed similar assays for SARS-CoV-2. They evaluated commercially available antibodies, some of which targeted SARS-CoV-2 epitopes that were conserved in SARS-CoV-2, while others targeted SARSCoV-2 specific glycoproteins, on SARS-CoV-2 infected formalin-fixed paraffin-embedded cell pellets [20]. The goal of this study was to expand the repertoire of commercially available antibodies and show their utility on autopsy and surgical specimens. Furthermore, we demonstrated that IHC is as sensitive as ISH for the detection of SARS-CoV-2.

In conclusion, we present a staining protocol and a list of commercially available antibodies for detection of SARS$\mathrm{CoV}-2$ on human formalin-fixed, paraffin-embedded tissue. The exact protocol can be rapidly applied in laboratories with the Leica automation or modified using the listed antibodies to fit the platform available. Widespread validation and implementation of assays to detect SARS-CoV-2 in tissue will enable advancing the understanding of this disease.

\section{Compliance with ethical standards}

Conflict of interest The authors declare that they have no conflict of interest.

Publisher's note Springer Nature remains neutral with regard to jurisdictional claims in published maps and institutional affiliations.

\section{References}

1. Zhou P, Yang XL, Wang XG, Hu B, Zhang L, Zhang W, et al. A pneumonia outbreak associated with a new coronavirus of probable bat origin. Nature. 2020;579:270-3.

2. Chen T, Wu D, Chen H, Yan W, Yang D, Chen G, et al. Clinical characteristics of 113 deceased patients with coronavirus disease 2019: retrospective study. BMJ. 2020;368:m1091.

3. Liu J, Zheng X, Tong Q, Li W, Wang B, Sutter K, et al. Overlapping and discrete aspects of the pathology and pathogenesis of the emerging human pathogenic coronaviruses SARS-CoV, MERS-CoV, and 2019-nCoV. J Med Virol. 2020;92:491-4.

4. Barton LM, Duval EJ, Stroberg E, Ghosh S, Mukhopadhyay S. COVID-19 autopsies, Oklahoma, USA. Am J Clin Pathol. 2020;153:725-33.

5. Wichmann D, Sperhake JP, Lütgehetmann M, Steurer S, Edler C, Heinemann A, et al. Autopsy findings and venous thromboembolism in patients with COVID-19: a prospective cohort study. Ann Intern Med. 2020:M20-2003.

6. Tian S, Xiong Y, Liu H, Niu L, Guo J, Liao M, et al. Pathological study of the 2019 novel coronavirus disease (COVID-19) through postmortem core biopsies. Mod Pathol. 2020;33:1007-14.

7. Su H, Yang M, Wan C, Yi LX, Tang F, Zhu HY, et al. Renal histopathological analysis of 26 postmortem findings of patients with COVID-19 in China. Kidney Int. 2020;S00852538:30369-0.

8. Barth RF, Xu X, Buja LM. A call to action: the need for autopsies to determine the full extent of organ involvement associated with COVID-19. Chest. 2020;S0012-3692:30687-5.

9. Wang F, Flanagan J, Su N, Wang LC, Bui S, Nielson A, et al. RNAscope: a novel in situ RNA analysis platform for formalin-fixed, paraffin-embedded tissues. $\mathrm{J}$ Mol Diagn. 2012;14:22-29.

10. Menter T, Haslbauer JD, Nienhold R, Savic S, Hopfer H, Deigendesch N, et al. Post-mortem examination of COVID19 patients reveals diffuse alveolar damage with severe capillary congestion and variegated findings of lungs and other organs suggesting vascular dysfunction. Histopathology. 2020.

11. Song Y, Liu P, Shi XL, Chu YL, Zhang J, Xia J, et al. SARSCoV-2 induced diarrhoea as onset symptom in patient with COVID-19. Gut. 2020;69:1143-4.

12. Larsen C, Bourne T, Wilson J, Saqqa O, Ma S. Collapsing glomerulopathy in a patient with coronavirus disease 2019 (COVID19). Kidney Int Rep. 2020;5:935-9.

13. Guzik TJ, Mohiddin SA, Dimarco A, Patel V, Savvatis K, MarelliBerg FM, et al. COVID-19 and the cardiovascular system: implications for risk assessment, diagnosis, and treatment options. Cardiovasc Res. 2020:cvaa106. [Epub ahead of print].

14. $\mathrm{Li} \mathrm{YC}$, Bai WZ, Hashikawa $\mathrm{T}$ The neuroinvasive potential of SARS-CoV2 may play a role in the respiratory failure of COVID-19 patients. J Med Virol. 2020. https://doi.org/10.1002/ jmv.25728.

15. Mao L, Jin H, Wang M, Hu Y, Chen S, He Q, et al. Neurologic manifestations of hospitalized patients with coronavirus disease 2019 in Wuhan, China. JAMA Neurol. 2020;77:1-9. [Epub ahead of print].

16. Farkash EA, Wilson AM, Jentzen JM. Ultrastructural evidence for direct renal infection with SARS-CoV-2. J Am Soc Nephrol. 2020. ASN.2020040432. [Epub ahead of print].

17. Calomeni E, Satoskar A, Ayoub I, Brodsky S, Rovin BH, Nadasdy T. Multivesicular bodies mimicking SARS-CoV-2 in patients without COVID-19. Kidney Int. 2020;98:233-4.

18. Shieh WJ, Hsiao CH, Paddock CD, Guarner J, Goldsmith CS, Tatti K, et al. Immunohistochemical, in situ hybridization, and 
ultrastructural localization of SARS-associated coronavirus in lung of a fatal case of severe acute respiratory syndrome in Taiwan. Hum Pathol. 2005;36:303-9.

19. To KF, Tong JH, Chan PK, Au FW, Chim SS, Chan KC, et al. Tissue and cellular tropism of the coronavirus associated with severe acute respiratory syndrome: an in-situ hybridization study of fatal cases. J Pathol. 2004;202:157-63.

20. Liu J, Babka AM, Kearney BJ, Radoshitzky SR, Kuhn JH, Zeng $\mathrm{X}$. Molecular detection of SARS-CoV-2 in formalin fixed paraffin embedded specimens. JCI Insight. 2020;5:e139042. 